\title{
LEMBRANDO EMERSON E THOREAU PARA PENSAR OS DEMÓNIOS DO PROGRESSO NA AMAZÓNIA
}

\author{
José Luís Garcia ${ }^{1}$ \\ Filipa Subtil $^{2}$
}

\begin{abstract}
RESUMO
Tendo em mente os efeitos socio-ambientais associados aos grandes projectos tecnológicos e de exploração económica da Amazónia, o artigo revisita as perspectivas críticas do entendimento tecnocrático do progresso moderno de dois vultos pioneiros do pensamento norte-americano, Ralph W. Emerson e Henry D. Thoreau. Os EUA são a principal potência industrial e económica do mundo e os seus padrões tecnológicos e modelo de desenvolvimento exercem atracção em muitas nações. Assim, a visão céptica de Emerson e Thoreau relativamente ao poder científico e tecnológico próprio do progressismo norte-americano surge como um alerta para os problemas que a Amazónia enfrenta gerados pelo colossalismo tecnológico, exploração da natureza e aniquilamento das comunidades indígenas.
\end{abstract}

Palavras-chave: Emerson. Thoreau. Amazónia. Colossalismo Tecnológico. Entendimento tecnocrático do progresso.

\begin{abstract}
In light of the social and environmental effects of the major projects involving technological and economic exploitation of the Amazon rainforest, this article revisits the critical approaches of two pioneering figures of North-American thought, Ralph W. Emerson and Henry D. Thoreau, to the technocratic understanding of modern progress. The USA is the world's leading industrial and economical power, and both its technological standards and its development model appeal to many other countries. Emerson and Thoreau's skeptical view regarding the technological and scientific influence of North-American progressivism emerges as a warning of the problems confronting the Amazon rainforest, brought on by the sheer magnitude of technological development, the exploitation of nature and the annihilation of indigenous communities.
\end{abstract}

Keywords: Emerson. Thoreau. Amazon. Technocratic Conception of progress. Technological Colossalism.

\section{INTRODUÇÃO}

Entre o século XVIII e meados do século XX, a ideia de que a história é o registo do progresso, considerado como crescimento do conhecimento científico, avanços das técnicas e melhorias contínuas das condições da vida humana, tornou-se a mais forte crença coletiva do

\footnotetext{
1 Investigador Principal. Instituto de Ciências Sociais, Universidade de Lisboa, Portugal. E-mail: jlgarcia@ics.ulisboa.pt

${ }^{2}$ Professora Adjunta. Escola Superior de Comunicação Social, Instituto Politécnico de Lisboa, Portugal. E-mail: fsubtil@escs.ipl.pt
} 
que é chamado mundo ocidental. Esta mentalidade acompanha o surto de novas técnicas e do novo espírito científico que começou a brotar nos finais da Idade Média europeia e se prolongou com as descobertas geográficas, a expansão marítima dos séculos XV e XVI e o movimento de ideias do Iluminismo. Em finais do século XVIII, a concepção do progresso registou uma inflexão de perspetiva de pendor tecnocrático. Enquanto para os principais expoentes do Iluminismo, as descobertas da ciência e as invenções técnicas eram consideradas necessárias, mas insuficientes para atingir o progresso geral, a nova concepção tendia a engrandecer o papel histórico da ciência e da tecnologia. Foi assim que uma consciência orgulhosa do domínio sobre a natureza, que se encontrava em rápida expansão, associada frequentemente a um ideal de conhecimento científico total, se tornou no âmago do progressismo euro-americano (L. MARX 2001 [1996], p. 312-337). Nos EUA, esta visão tomou conta do imaginário colectivo e o seu poder tecnológico, industrial e económico engrandeceu até ser hegemónico e tornado um exemplo.

$\mathrm{Na}$ contra-corrente de um tal entendimento de predominância do factor técnico no progresso moderno, Ralph Waldo Emerson (1803-1882) e Henry David Thoreau (1817-1862), duas das figuras mais celebradas da cultura, literatura e humanidades dos EUA, não compreendiam a natureza como um mero repositório de possibilidades para dominar e explorar e combateram a crença no progresso tecnológico, industrial e económico como fim em si mesmo. Tendo vivido no século XIX, participaram ativamente em muitos debates intelectuais da sua época, em especial os que se desenvolveram em torno da transformação da América do Norte numa potência industrial e económica. Integraram o "transcendentalismo norte-americano", um movimento intelectual e espiritual que irrompeu na Nova Inglaterra como uma manifestação de resistência ao racionalismo do século XVIII, sobretudo às suas versões mais categóricas. Foram também expoentes do chamado "ideal pastoral norte-americano", que postulava a possibilidade de harmonizar o emergente desenvolvimento industrial e a manutenção do mundo natural dos EUA. A expressão machine in the garden, cunhada por Leo Marx ([1964] 2000), simboliza esta convicção - a tecnologia moderna poderia ser acolhida pelo continente americano virgem. Todavia, na passagem para a segunda metade do século XIX, Emerson e Thoreau exprimiram, cada um à sua maneira, um ceticismo acentuado relativamente à idolatração do poder científico e tecnológico própria das variantes “infinitistas" do progressismo moderno. 
A perspectiva destes escritores colide hoje frontalmente com o que se tornou a realidade social norte-americana, empenhada na guerra contra a natureza, na criação incessante de riqueza material e no domínio cultural e político concretizado pela indústria cultural, tecnologias da informação e aparelho militar. Essa é também a representação que uma grande parte do mundo faz dos EUA, procurando muitos países imitá-los com afã. Emerson e Thoreau privilegiaram refletir a partir da experiência vivida e em vez de grandes sistemas escreveram ensaios, escritos literários e relatos de episódios de vida. Muitos dos seus temas e reflexões anteciparam a atual erosão das ideias progressistas e a reacção que emergiu nas últimas décadas do século XX, oposta à tendência ideológica favorável a um progresso acima de quaisquer valores. As lutas em torno das megaestruturas tecnológicas, da devastação das florestas e dos rios, dos organismos geneticamente modificados e do agronegócio ${ }^{3}$, das alterações climáticas, são exemplos do questionamento e da falta de confiança de largos sectores da sociedade no que tange as lógicas imperantes e entrelaçadas da ciência, da tecnologia e da indústria. Este texto sustenta que os problemas que a Amazónia enfrenta, assolada por políticas de gigantismo e colossalismo tecnológico, de exploração desmesurada da natureza e destruição de comunidades autóctones, podem beneficiar da releitura do pensamento de Emerson e Thoreau.

\section{CONTEXTOS}

Emerson e Thoreau viveram em Concord, um pequeno povoado rodeado de florestas da Nova Inglaterra, que foi o lugar do primeiro grande confronto da Revolução Americana. Mantiveram sempre uma profunda ligação a este lugar que acolheu a primeira comunidade rural de artistas e onde floresceu o movimento transcendentalista. A Concord e ao transcendentalismo estão também associados intelectuais e escritores como Nathaniel Hawthorne, Margaret Fuller, Bronson Alcott e William E. Channing, entre outros. Este movimento começou a organizar-se em 1836 e entre 1840 e 1929 publicou, de forma intermitente, uma revista trimestral, The Dial ${ }^{4}$. Vários dos seus participantes estiveram comprometidos com os esforços reformistas, fizeram parte do movimento abolicionista ou coabitaram em comunidades utópicas experimentais como Brook Farm.

\footnotetext{
${ }^{3}$ Relativamente a esta importante problemática na literatura brasileira, ver Lacey (2006) e Mariconda e Ramos (2003).

${ }^{4} \mathrm{Na}$ sua primeira forma, entre 1840-1844, foi a publicação oficial do movimento.
} 
Emerson é considerado o primeiro pensador genuinamente norte-americano e a sua conferência "The American Scholar", proferida a 31 de agosto de 1837, na Universidade de Harvard, é uma verdadeira declaração de independência cultural dos EUA. De acordo com Emerson, seria o pensamento nativo, alicerçado no conhecimento da Natureza e do ser humano, que poderia libertar a criatividade. Thoreau encontrou em Emerson um mentor com quem manteve uma prolongada relação pessoal e intelectual, embora pautada pela independência, num tempo marcado pela erupção do sentimento democrático na América do Norte (COSTA, 2014, p. 13).

Estes escritores canónicos dos EUA assistiram a uma das primeiras grandes crises financeiras do capitalismo, o chamado "Pânico de 1837", desencadeada pela especulação em redor do sistema bancário, que levou vários bancos à insolvência. Uma das sequelas desta crise foi a desconfiança dos meios intelectuais para com o espírito comercial e o materialismo. Estes passaram a ser vistos como fatores que conduziram quer ao menosprezo da vida cultural, quer ao que consideraram ser o declínio do caracter da jovem nação norte-americana. Tem assim sentido que Emerson e Thoreau tenham defendido a auto-confiança como elemento que alicerçava a genuína personalidade humana, aquela que se poderia afirmar diante de condições difíceis.

Os transcendentalistas tinham como convicção fundamental a unidade do mundo e de Deus, não dissociavam a ideia de Deus da ideia de natureza e acreditavam que a mente humana partilhava da razão divina. A partir desta carga espiritual, postularam uma atitude vital virada para a reflexão interior, para o auto-conhecimento e a singularidade de cada indivíduo. A crença na identificação da alma individual com Deus encorajou-os a elaborar um conceito de "cultura do eu" e a segui-lo como um caminho íntimo, de reflexão pessoal, fora do ruído do mundo e subordinado a regras naturais. Cultivaram, por isso, o individualismo e a desconfiança nas instituições. A ideia da unidade da natureza levou-os a encontrar elos entre as mais diversas formas de vida e as manifestações da natureza por toda a parte.

Tendo raízes na antiguidade greco-romana e na revelação judeo-cristã, a ideologia do progresso só no século XVIII se tornou simultaneamente uma teoria global, uma concepção da história e uma crença dominante. A ideia moderna de progresso envolve uma perspectiva do mundo que enfatiza a criatividade em detrimento da perpetuidade, a história como realização linear orientada para um fito definido, em vez da reiteração do mesmo, e uma capacidade humana soberana face à natureza, e não subordinada. Para Emerson e Thoreau, as 
capacidades da mente humana potenciavam o conhecimento da natureza por parte dos humanos, mas tal não significava que estivesse reservado a estes um papel como seres supostamente superiores destinados a submeter a natureza e a serem senhores do mundo. Os seres humanos eram pensados como parte integrante da natureza e as suas capacidades deveriam ser orientadas para a bem habitar. Nestes autores revela-se uma crença na primazia da natureza sobre a sociedade, uma tendência para a insubordinação contra as instituições e o acolhimento na mãe natureza representativas de uma certa sensibilidade romântica ${ }^{5}$.

\section{EMERSON: CONTRADIÇÕES NA MACHINE IN THE GARDEN}

No século XIX, num momento em que a industrialização estava a revolver alguns países da Europa ocidental, o ideal pastoral norte-americano postulava a possibilidade de conciliação entre a natureza e o mundo manipulador e dinâmico do progresso material. Emerson é considerado por muitos autores como tendo sido, até sensivelmente à primeira metade do século XIX, o responsável pela narrativa norte-americana sobre os laços entre o progresso e a natureza.

Acima de tudo, Emerson punha o acento na liberdade e no começo que toda a acção humana representa. "Um homem deveria aprender a detectar e a observar mais a luz que atravessa interiormente a sua mente como um raio do que o brilho do firmamento de bardos e sábios" (2009, p. 10). A sua adesão ao progresso era temperada pela reserva que mantinha no que diz respeito ao "espírito societal". Por isso, foi-lhe possível dizer serenamente: "Todos se gabam do progresso social e ninguém progride" (2009, p. 32). Ou de modo mais argumentado: “A sociedade nunca progride. Recua tão depressa de um lado como avança de outro. Passa por mudanças contínuas; é bárbara, civilizada, cristã, rica, científica, mas essa mudança não significa melhoria" (Idem).

\footnotetext{
${ }^{5}$ Entende-se aqui o romantismo não meramente como um estilo literário, mas como um movimento que se manifesta em todos os campos da vida cultural. Abrangendo uma pluralidade de correntes, caracteriza-se por constituir um protesto contra a emergência da civilização capitalista moderna e o desenvolvimento industrial e empresarial baseado na racionalidade burocrática, no domínio mercantil e na tecnificação e quantificação da vida social. Michael Löwy (2016), um dos grandes estudiosos do romantismo na ótica focada, elenca diversas variantes da sensibilidade romântica: o romantismo conservador, defensor do restabelecimento dos privilégios e hierarquias do Antigo Regime; o romantismo revolucionário, cujo fito é um retomar um passado comunitário para o guiar em direção a um futuro utópico; e o romantismo obscurantista e intolerante à crítica humanista da racionalidade instrumental e burocrática. Emerson e Thoreau aproximam-se da segunda variante, embora sem a conotação revolucionária no sentido sócio-político (próprio do marxismo), antes privilegiando uma forte dimensão ecológica.
} 
As palavras que Emerson dedica ao "homem civilizado" revelam tanta melancolia como pouca complacência: "O homem civilizado construiu uma carroça, mas perdeu o uso dos pés. É amparado por muletas, mas falta-lhe o apoio dos músculos. [...] Os seus blocos de notas debilitam-lhe a memória, as suas bibliotecas sobrecarregam-lhe a mente" (2009, p. 32). Este tipo de reflexão era um antídoto para qualquer consagração do avanço tecnológico que estivesse descontextualizado dos fins humanos que deveria servir: "As técnicas e os inventos de cada época são apenas as suas roupagens, não fortalecem os homens. É possível que o mal resultante dos progressos da máquina contrabalance o bem que ela traz" (2009, p. 33).

No entanto, a máquina era, para Emerson, um produto da capacidade do entendimento humano de transformar o que era natural num artefacto. A máquina era um resultado dessa faculdade humana e esta era, por seu turno, fruto dos bens oferecidos pela Natureza. A máquina não era mais do que a natureza convertida noutro elemento. No ensaio "A Natureza", ilustra assim essa dádiva da Natureza:

Quando acode às necessidades do homem, a Natureza não é apenas a matéria, é também o processo e o resultado. Todos os seus elementos trabalham, de mãos dadas, para benefício do homem. O vento espalha a semente, o Sol evapora o mar, o vento sopra o vapor para os campos; do outro lado do planeta, o gelo condensa a chuva neste lado; por sua vez, esta alimenta a planta, a planta o animal e, deste modo, a infindável circulação da caridade divina alimenta o homem (EMERSON, 2009 [1836], p. 78).

Junto com a beleza, a linguagem (sendo esta um veículo do pensamento), a disciplina e a tecnologia são incluídas na lista dos bens essenciais que os humanos acolhem da Natureza:

\begin{abstract}
As artes utilitárias são reproduções, ou novas combinações resultantes da inteligência humana, dos mesmos benfeitores naturais. O homem já não espera pelos ventos favoráveis, mas, graças ao vapor, dá vida à fábula do saco de Éolo e transporta os trinta e dois ventos na caldeira do seu barco. Para atenuar as fricções, pavimenta as estradas com barras de ferro e, montado numa carruagem que leva atrás de si um carregamento de homens, animais e mercadorias, dispara pelos campos, de cidade em cidade, como a água e a andorinha fendem os ares (EMERSON, 2009 [1836], p. 78-79).
\end{abstract}

$\mathrm{Na}$ verdade, Emerson tanto elogiava a tecnologia como glorificava a Natureza. A Natureza era serva do humano, mas apenas no sentido em que ela era a verdadeira soberana, ela, a quem tudo se devia. Ao servir-se da natureza, através da máquina, o ser humano era senhor apenas de um poder delegado. Instruídos pelos ensinamentos que a experiência com a 
Natureza possibilitava, os norte-americanos teriam a oportunidade de tornar a América num jardim, pensava Emerson.

Todavia, em finais de 1840, este autor manifestava já sinais de cepticismo acerca da compatibilidade entre o ideal pastoral e o progresso tecnológico e industrial. O historiador Leo Marx situa este ponto de viragem no contexto da segunda visita de Emerson à Inglaterra, em 1847 (2000, p. 263). Assim, English Traits, de Emerson, publicado em 1856, pode ser apreciado como um dos seus primeiros e mais penetrantes estudos da nova cultura do industrialismo. O livro aparentemente reporta-se à Inglaterra, mas teria como objectivo discutir o futuro. Emerson prossegue a metáfora da máquina no jardim, afirmando que a Inglaterra era um jardim. Presta ainda tributo à Revolução Industrial, apelidando-a de maravilhosa maquinaria que diferenciaria aquela época de qualquer outra. Todavia, na segunda parte do livro, o desenvolvimento tecnológico é também considerado como causa de alienação. A maquinaria estava a desumanizar o utilizador e a demonstrar que era ingovernável (L. MARX, 2000, p. 263).

Parte inalienável do progresso tecnocrático é a utopia da comunicação e da interconexão global incentivada pelos novos sistemas tecnológicos, infraestruturas e redes técnicas. A comunicação, ao integrar a ordem da vinculação, a ordem do religare dos seres humanos, presta-se a ser um âmbito para projecções utópicas. A comunicação entre os humanos tende a ser imaginada como podendo desimpedir muitas das principais dificuldades e obstáculos da vida colectiva. A cada feito técnico na comunicação física (vias rodoviárias e ferroviárias, meios de transporte terrestre, marítimos, aéreos, pontes, túneis...) e simbólica (impressão, jornais, livros, telégrafo, telefone, rádio, televisão, Internet...) do mundo moderno ocidental correspondeu sempre algum tipo de excesso e apologia pelas suas presumíveis virtudes libertadoras. Nos dias de hoje, com as capacidades de transporte de pessoas e produtos por todo o planeta, com a Web como rede técnica capaz de permitir interacções humanas, todo um reino de promessas é tomado por muitos como podendo converter-se em realidade. A este respeito, nenhum tipo de inclinação prometeica pode ser imputado a Emerson. Com efeito, duvidou sempre da verdadeira possibilidade de ligação indivisa entre os humanos ou que a tentativa dessa ligação fosse simplesmente bem-aventurada. No seu ensaio "A Experiência”, questiona: “Terá sido Boscovitch quem descobriu que os corpos nunca estiveram em contacto?". A sua resposta não é consoladora para quem acredita na boa-fé da comunicação: "Pois bem, as almas também nunca tocam os seus objectos. Um mar 
intransponível lança as suas vagas silenciosas entre nós e as coisas que desejamos e com as quais conversamos" (2009 [1844], p. 140). Emerson entende a comunicação, como bem sublinha John D. Peters, "como um assunto de dar e receber sem qualquer coordenação entre os dois" (1999, p. 157). Em contrapartida, essa improbabilidade da comunicação oferece a razão para festejar o universo como uma disseminação permanente para todos que tenham sentidos para perscrutar. Para Emerson, é preciso saber ver a natureza; nos bosques encontra-se algo de mais íntimo do que nas ruas ou nas aldeias; os campos proporcionam a sugestão de uma relação oculta entre o homem e o reino vegetal.

Na sua perspectiva, o afastamento infinito entre as pessoas é o quadro da vida humana. Em “A Confiança em si”, interroga: “o teu amor pelo que está longe não será um sinal de desprezo pelo que está perto?” (2009 [1841], p. 13). A disposição moderna para a viagem desponta como uma fuga de si próprio: "Quem viaja para se distrair ou para obter qualquer coisa que não leva consigo, evade-se de si mesmo e envelhecerá entre coisas antigas, mesmo na flor da idade". Esta reflexão leva-o a dizer que "Viajar é o paraíso dos tolos [...]. Em casa sonho embriagar-me de beleza e perder a minha tristeza em Nápoles; aí, ao meu lado, encontro a austera realidade: o eu triste, implacável, precisamente aquele de quem fugira" (2009 [1841], p. 30). Compreendemos assim também que a solidão não deva ser receada ou considerada como algo nefasto, mas antes uma verdadeira opção de vida. Em "A Natureza" afirma: "Para encontrar a solidão, um homem tem de deixar tanto o seu quarto como a sociedade. Quando escrevo ou leio nunca estou só, apesar de ninguém estar comigo. Mas se alguém quer estar sozinho que contemple as estrelas" (2009 [1836], p. 75).

A solidão é contraposta a uma vida vivida segundo a opinião dos outros, a qual é largamente infundida pelos meios modernos de comunicação de massa. Neste sentido, argumenta: "É fácil viver no mundo segundo a opinião dos outros; é fácil viver na solidão seguindo a nossa própria opinião, mas grande é o homem que, entre a multidão, guarda, com perfeita amenidade, a independência da solidão" (2009 [1841], p. 14).

É possível sustentar que em Emerson se encontram já presentes alguns dos traços do espírito que no século XX gerou as "ecoreligiões" (GINER, 2003) e que foi, como iremos ver de seguida, continuado de forma ainda mais vigorosa por Thoreau. As preocupações e inquietações ambientais, ecológicas e até cósmicas específicas do nosso tempo têm vindo a ser incorporadas no mundo da fé e das atitudes religiosas. A mudança ambiental, ao abranger a eventual extinção da natureza tal como a temos conhecido até ao presente, é percebida pelos 
seres humanos como uma modificação de dimensão universal. Os cultos ecológicos e ambientais que assomaram ao longo do século XX articulam-se com um projecto de redenção, pois a salvação da humanidade passa pela salvação da natureza e pela atribuição de um carisma à própria natureza. Compreende-se, pois, que a natureza se tenha tornado objecto de deferência e culto (cf. GINER, 2003, p. 180).

\section{THOREAU: DIAGNÓSTICO DE UMA EMERGENTE CULTURA INSANA}

Como Emerson, Thoreau propugnava por princípios de vida que possibilitassem habitar plenamente o mundo, conhecê-lo em completa liberdade e com todos os sentidos, com consciência que integra a natureza e assim atingir a condição da autenticidade do ser humano. A sua obra mais conhecida, com estatuto de clássica e de culto, é Walden ou a vida nos bosques (2009 [1854]), que tem como eixo o bosque e o recolhimento numa cabana. Menos conhecido é outro seu longo ensaio, A Week on the Concord and Merrimack Rivers (1849), dedicado a uma viagem pelos rios enunciados no título do livro. As duas obras são inseparáveis e podem ser consideradas um diptíco.

A leitura de Walden é particularmente apropriada para compreender o pensamento de Thoreau relativamente ao empenho das sociedades modernas na mudança tecnológica e industrial e às expectativas de que era acompanhada quanto ao aumento e aos hipotéticos benefícios da riqueza material. Outro ensaio breve, Uma vida sem princípios (2014 [1863]), pode ser igualmente uma boa fonte para aceder ao seu exame de um sistema cultural que, mais de uma vez, encara como sendo genuinamente doentio.

Desde o capítulo inicial de Walden, intitulado "Economia", Thoreau confronta-se com o esforço humano absorvido pela sociedade industrial, com o devoção pelos meios técnicos e pelo dinheiro, com os desvarios do consumo que começaram a irromper, com a degradação da qualidade da comunicação que afectava o esforço de identidade e auto-confiança do sujeito. Sustenta Thoreau que as pessoas comuns e os trabalhadores se deixaram absorver por preocupações artificiais e tarefas superficialmente ásperas que faziam com que não pudessem colher os frutos mais saborosos da vida, dispor de tranquilidade para uma genuína integridade na vida quotidiana ou para manter relações mais humanas com os outros humanos. Para que o seu trabalho não fosse "depreciado no mercado" não tinham condições de serem outra coisa que não máquinas (2009, p. 20). 
Considerações muito próximas às anteriores encontram-se também no texto Uma vida sem princípios (2014 [1863]), onde desaprova repetidamente os elogios à actividade, ao trabalho e ao emprego como único objectivo de obter um salário sem ponderar a sua razão de ser. É melhor caminhar nos bosques do que os arrasar para os tornar rentáveis e, no entanto, os que passeiam são considerados vagabundos e os que escavam são considerados cidadãos "empreendedores e ambiciosos", citando as suas palavras (2014, p. 30, 31). Thoreau zomba dos anúncios de emprego para jovens activos, como se a actividade, como escreve, "fosse todo o capital de um jovem". O “empreendorismo", exemplifica, confunde-se com o espírito dos que se dedicavam à corrida ao ouro da Califórnia e a muitos negócios eivados de imoralidade. Num tempo como o actual, em que se procura gerar aquilo a que se chama emprego sem considerar o que plenamente se joga no trabalho que se vai efectuar e onde só importa conseguir dinheiro, num tempo que louva o chamado espírito empreendedor, é assombroso ler a proclamação de Thoreau de que não precisa de emprego (2014, p. 33). Não que o nosso autor desdenhe, como ele próprio escreve, "ganhar a vida", mas importa que seja "de forma útil e honrosa, mas também e ao mesmo tempo de forma atraente e gloriosa..." (2014, p. 36).

Em Walden, Thoreau afirma sem hesitação que os "progressos modernos" são “inventos... (que) ... costumam ser belos brinquedos que distraem a atenção das coisas sérias", são "meios aperfeiçoados para atingir um fim que não se aperfeiçoou..." (2009, p. 68). Denuncia assim a primazia crescente de muitos meios técnicos sobre os fins que pressupostamente deveriam servir e que colocam os seres humanos numa condição de falsa necessidade. "Os homens transformaram-se nos instrumentos dos seus instrumentos", escreve (2009, p.53).

Thoreau salienta, sobretudo, os malefícios da tendência para tornar absolutos tais progressos e meios. São várias as páginas que dedica à tendência para o consumo excessivo, que orienta os esforços de muitos indivíduos em direcção ao mundo do dinheiro e das mercadorias. É neste âmbito que rejeita a veneração pela "deusa moda" que faz com que, em Paris, quando "a macaca-mor põe um gorro de viajante... logo na América todas as macacas copiam" (2009, p. 40); ou o endividamento por casas luxuosas que conduzem muitos a ser "perseguidos até à morte para pagar a renda". Nestes ditos "progressos modernos", considera Thoreau, "há muita ilusão, mas nem sempre há um avanço positivo" (2009, p. 68). 
Como ilustração desse fascínio, Thoreau oferece precisamente um exemplo no âmbito dos transportes, o caminho-de-ferro: "E se as ferrovias não forem construídas como chegaremos a tempo ao céu?", pergunta com ironia (2009, p. 110). Thoreau sabia que as grandes concessões de terras por parte dos governos federal e estadual (73 milhões, até finais do século XIX) e um forte investimento económico que favorecia grupos monopolistas (em 1897 tinham sido investidos mais de 10000 milhões de dólares) eram o combustível em que assentava o ímpeto pelo grande desenvolvimento ferroviário dos EUA. Percebe-se, deste modo, a resposta dada por Thoreau à interrogação que formulou: "nós não andamos sobre os caminhos-de-ferro, eles é que andam sobre nós" (2009, p. 110). Estas palavras ganham ainda mais sentido quando, no mundo contemporâneo se valorizam as estruturas tecnológicas de dimensões gigantescas, embora esta seja uma manifestação com tradições muito antigas na monumentalidade de sociedades sob lideranças despóticas, casos do Egipto antigo e da civilização azteca com as pirâmides, da Roma imperial e os coliseus e arcos do triunfo, da Idade Média europeia e suas catedrais medievais. Empreendimentos colossais, na forma de canais que ligam oceanos, mega-barragens, grandes pontes ${ }^{6}$ e túneis, edifícios arranha-céus, estradas e linhas ferroviárias que trespassam montanhas e esventram florestas (como a Transamazônica ${ }^{7}$, no Brasil e Perú, e a ferrovia que liga Pequim a Lhasa, no Tibete), são modalidades de tecnoeconomia maximalista ditadas quer pelo movimento próprio do capitalismo, quer pela vertigem de grandeza da capacidade demiúrgica humana através dos artefactos e sistemas tecnológicos ${ }^{8}$. As redes de transportes não aproximam apenas populações que estão distantes umas das outras; são estruturas que servem finalidades económicas de importação e exportação de produtos, que alteram os preços e redimensionam o mercado; servem ainda de meio através do qual o poder político se impõe do centro para as periferias e a dinâmica que implementam contribui para a destruição das formas económicas frágeis dessas periferias e os modos de vida nelas tradicionais, quer como efeito dos movimentos migratórios que estimulam, quer pelos efeitos dos mercados nacionais e globais (Carey, 2009 [1983]; Subtil, 2014).

Similarmente aos sistemas de transporte, também com os de informação se esquecem os fins que dão significado à sua existência. "Apressamo-nos a construir um telégrafo

\footnotetext{
${ }^{6}$ Ver Garcia e Subtil (1998).

${ }^{7}$ Ver Souza (2018).

${ }^{8}$ A respeito do conceito de "maximalidade tecnológica", ver McGinn (1994, p. 58). Na literatura portuguesa, ver Martins (2012, p. 433-451).
} 
magnético entre o Maine e o Texas", escreve Thoreau, "mas pode acontecer que o Maine e o Texas não tenham nada de importante a comunicar". E acrescenta:

\begin{abstract}
Ambos podem achar-se na situação daquele homem que, ansioso por ser apresentado a uma ilustre dama surda, quando a ocasião se lhe apresentou, com o ampliador colocado na mão, não teve nada a dizer. Como se o objectivo principal fosse falar depressa e não com bom senso. Desejamos construir um túnel sob o Atlântico e trazer o velho mundo para perto de nós com algumas semanas de antecedência, mas pode muito bem acontecer que a primeira notícia a chegar aos ouvidos americanos seja que a princesa Adelaide está com tosse convulsa (2009, p. 68).
\end{abstract}

Thoreau partilhava com Emerson de um conceito vital voltado para a prospecção interior do indivíduo e para a sua incorporação na natureza, por ser parte dela e capaz de entendê-la experienciando-a. Não denota, por isso, apreço pela transmissão à distância constante e massiva de informações, não revela entusiasmo pelas novidades disseminadas pela imprensa, nem pelas correntes de opinião desencadeadas pelos meios de comunicação. Em Walden, chega a confessar que até "podia passar facilmente sem correio", pois considera “que há pouquíssimas comunicações importantes feitas por seu intermédio” (2009, p. 111). De forma desassombrada, afirma que “... não [recebeu] toda a vida mais do que uma ou duas cartas que valessem a tarifa postal...” (idem). E mantém a mesma posição relativamente ao mundo das notícias produzido pela industrialização da imprensa. Vejamos as suas palavras a este respeito:

\footnotetext{
Também estou certo de que nunca li nos jornais nenhuma notícia notável. Se já lemos a respeito de um homem assaltado ou assassinado, ou morto num acidente, ou de uma casa incendida ou do naufrágio de um navio, ou da explosão de um vapor, ou de uma vaca atropelada no Caminho de Ferro do Oeste, ou da morte de um cão raivoso, ou de uma nuvem de gafanhotos no inverno - nunca mais precisaremos de ler a respeito de coisas semelhantes. Basta uma vez (2009, p. 112).
}

"Todas as chamadas novidades" dos jornais, diz Thoreau, "não passam de bisbilhotices, e as pessoas que encarregam de editá-las e lê-las, não passam de velhinhas a tomar chá" (idem). No entanto, "não são poucos os ávidos por bisbilhotices", lamenta-se. As notícias, no fundo, são uma replicação dos mesmos acontecimentos, acontecimentos a maior parte das vezes sem verdadeira importância. Relativamente às informações vindas da Inglaterra, graceja Thoreau, "por pouco a última notícia significativa vinda de lá não foi a da Revolução de 1649” (idem). Thoreau antecipa neste diagnóstico as torrentes de insignificância que passaram a ser comuns nos grandes meios de comunicação de massa e se tornaram 
exacerbadas nas chamadas redes sociais, com vastas implicações na cultura e na vida social e política do mundo contemporâneo. Em Uma vida sem princípios, escreve:

\begin{abstract}
Hoje, sem dúvida, muito podemos envergonhar-nos de confessar o que lemos ou ouvimos. Desconheço o motivo da trivialidade das minhas notícias - ao considerar tudo aquilo que são os nossos sonhos e expectativas, porque é que a nossa progressão é tão escassa. As notícias que ouvimos, na sua maioria, não nos oferecem novidade alguma. São a mais rançosa repetição. Sempre ficamos com a tentação de perguntar a razão pela qual é dada tanta importância a qualquer experiência pessoal, será só para que, passados vinte e cinco anos, encontremos aquele escrivão do cartório dos sucessos, um tal Hobbies, que nos perguntará: Então, nem sequer te mexeste um centímetro? Como esta são as notícias do dia-a-dia. Os seus factos parecem pairar na atmosfera, insignificantes como os espórulos dos fungos, que se acomodam num talo abandonado ou na superfície das nossas mentes que lhes fornecem o solo em que podem crescer, como parasitas. Devíamos libertar-nos das notícias deste género. [...] Não vivemos para distracções ociosas (2014 [1863], p. 48, 49).
\end{abstract}

As suas palavras a respeito da imprensa compreendem-se como reflexão sobre o facto completamente novo à escala histórica do sugestionamento entre os indivíduos à distância impulsionados pelos meios modernos de informação. Afastados fisicamente uns dos outros, não se vendo e não se tocando, dispersos por territórios extensos, lendo as notícias cada um em sua casa, os sujeitos pressentem que uma ideia ou vontade é compartilhada no mesmo momento por um grande número de outros, embora quem leia a imprensa não tenha geralmente consciência de estar a ser sujeito à influência persuasiva e irresistível que dela irradia. Foi esta capacidade dos media modernos - entretanto muito ampliada pela rádio, TV e hoje pela Internet - em formar correntes mentais sobre temas susceptíveis de captar a atenção de muita gente, assim como de difundir rumores, bisbilhotices e fake news em todas as áreas ${ }^{9}$ (não só políticas, mas também científicas, sociais, comerciais, desportivas, etc.), que Thoreau bem compreendeu e assinalou nas suas consequências.

Fazendo-nos lembrar as palavras de Emerson sobre a viagem, para Thoreau, a imersão do indivíduo no caudal contaminado das correntes mentais faz-se à custa do seu afastamento de si próprio, da procura da sua identidade; a aproximação ao que está distante fisicamente pelas técnicas de transporte e informação faz-se à custa do aumento do distanciamento com as comunidades próximas e com a natureza. Diz Thoreau: "Na mesma proporção em que a nossa vida interior começa a fraquejar, passamos a ir, de forma mais constante e desesperada, à estação dos correios." O sujeito que sai da estação dos correios, orgulhoso da correspondência

\footnotetext{
${ }^{9}$ Sobre a mentira, ver Subtil (2015).
} 
que acaba de receber, é um indivíduo que "já não ouve notícias de si próprio há muito tempo." Ler um jornal por semana, apenas um, é já demasiado para Thoreau. Confessa em Vida sem princípios que tentou manter essa prática semanal, mas ao fazê-lo como que abandonou a sua "região natal". É improvável estar longe e perto ao mesmo tempo: "Não se pode servir a dois senhores. É necessário mais do que a vivência de todo um dia para conhecer e possuir toda a riqueza dos eventos daquele mesmo dia" (2014, p. 47-48). As promessas de libertação que os transportes modernos e a imprensa ofereceram não foram realmente comungadas por Thoreau. Procurou a auto-confiança do humano consigo próprio e não o orgulho prometeico, a suposta confiança dada pelo poder da tecnologia moderna. Em sua opinião, é essa cultura do eu que dá fundamento ao governo e aos direitos cívicos, uma condição essencial da república.

Apesar de mais jovem, Thoreau faleceu antes de Emerson. Este, no elogio fúnebre que lhe fez, recordou que "era um prazer e um privilégio passear com ele", uma vez que “conhecia tão bem o campo como uma raposa ou um pássaro e cruzava-o livremente por caminhos desconhecidos por todos". Obedecer a um tal guia para caminhadas, diz Emerson, era estar certo de que a "recompensa era grande" (1862). E, de facto, Thoreau é autor de um dos mais celebrados escritos sobre a caminhada (2012 [1854]). O percurso físico que Thoreau proclama com o caminhar é no fundo uma expedição interior em direcção a uma vivência em liberdade e que sabe limitar-se ao fundamental.

\section{NOTAS FINAIS}

A Emerson e Thoreau assentam bem as palavras que Max Horkheimer escreve numa passagem de $O$ Eclipse da Razão, "os próprios pioneiros americanos não hipostasiavam os meios como fins" (2015 [1947], p. 168). O teórico alemão sublinha que, diante do dealbar de um mundo que iria ser revolvido pela grande indústria e pela alta tecnologia, as primeiras grandes figuras norte-americanas do pensamento e das letras imaginaram nos seus sonhos "os prazeres de um universo menos dinâmico e muito mais repousante. Provavelmente atribuíam um valor positivo à 'fruição estética da contemplação passiva' nos seus conceitos de felicidade ou no seu ideal de uma cultura ainda por adquirir" (idem). As ideias de Emerson e Thoreau revelam que nem todos estavam de acordo com um projecto de sociedade dedicada ao aumento da potência industrial e ao crescimento da riqueza e que houve imaginação para outros rumos mais sensíveis à dignidade social e à preservação da natureza. No entanto, a 
história do mundo moderno tomou outro sentido mais pautado pelo sonho demiúrgico dos seres humanos enquanto deuses das máquinas e pela perseguição da ganância económica.

Desde há várias décadas estamos tão habituados à cadência da mudança científica e tecnológica, impulsionadora da criação de novas indústrias, que quase não nos causa espanto. As forças que são largamente o motor das inovações tecnológicas e industriais, os Estados, as indústrias, as grandes corporations e os departamentos científicos, técnicos e de engenharia das universidades e laboratórios, têm vindo a agir como se restasse apenas aos cidadãos adaptarem-se às transformações no seu mundo estimuladas pelos produtos da cultura da inovação tecnológica que busca o lucro económico e pela velocidade da mudança tecnológica ${ }^{10}$. Tudo se passa como se esta não necessitasse de qualquer justificação, como se fosse conforme um plano imanente impossível de cessar ou que não deve ser interrompido. Mais ainda, os conflitos em torno da realização de mega-estruturas (estradas, pontes, túneis, hidrelétricas,...) são ainda frequentemente interpretados, mesmo pelos sectores que estão preocupados com a desigualdade social e pretendem erguer um mundo mais justo, como sendo meras reacções conservadoras aos paladinos do progresso que querem fazer triunfar a modernidade. Todavia, é cada vez mais evidente a dificuldade de muitos grupos humanos sobreviverem às actuais condições económicas ou se ajustarem às inovações tecnológicas, bem como aos efeitos desse desajustamento e das externalidades nocivas no ecossistema global. As forças propulsoras da inovação tecnológica estão mais movidas por objectivos eminentemente comerciais, tecnocráticos e de poder do que propriamente em contribuir para que o mundo social seja menos desigual e violento ou menos destruído ecologicamente.

O mundo dos nossos dias encontra-se numa profunda crise que não é apenas económica e social, envolvendo também o tipo de conhecimento científico predominante e muitas opções tecnológicas que se apresentam como sofisticadas pese embora o seu lado bárbaro, uma relação com o mundo natural que neste vê somente um recurso a ser incessantemente explorado ou sujeito a manipulação. No entanto, apesar da exponenciação dos riscos, das incertezas e das catástrofes ligadas à ação humana, como o aquecimento climático, a extinção da biodiversidade, o aumento da pobreza, o alastramento das guerras, o tipo de economia predatória e egoísta que domina os sistemas produtivos e condiciona as sociedades teima em ver-se como universal, como pináculo da humanidade, como fim da

\footnotetext{
${ }^{10}$ Sobre o tópico da inovação, ver Garcia (2012). Para uma relação entre inovação e neoliberalismo no Brasil, ver Oliveira (2014).
} 
história. Os crédulos deste modelo económico e da tecnociência guiada por interesses mercantis, que estão a converter os organismos biológicos e as florestas em mais-valia, convidam-nos a fazer pequenas mudanças ou a ter paciência, a continuar esta senda, e isto num tempo em que quer a humanidade, quer a natureza estão em causa. Por todo o mundo, e a uma cadência crescente, o tecnofanatismo tem vindo a gerar tecno-calamidades ${ }^{11}$.

Emerson e Thoreau ofereceram uma visão céptica e mesmo discordante do projecto de progresso decorrente do racionalismo moderno no seu entendimento mecanicista, economicista e tecnocrático. A tendência para uma maior desvinculação entre o mundo dos seres humanos e a natureza que as tecnologias modernas impulsionaram, assim como a quimera da comunicação global, não foram partilhadas por Emerson e Thoreau. No âmbito da história das ideias, estão na contracorrente das profecias industrialistas e tecnológicas de pensadores como o Conde de Saint-Simon e os seus influentes discípulos que viveram sensivelmente no mesmo período (entre finais do século XVIII e a primeira metade do século $\mathrm{XX)}$ e que tanta influência exerceram na formação do movimento histórico da filosofia positiva. Lembremos que, para esta corrente, uma sociedade científico-industrial teria o condão de abrir a possibilidade de superar as condições de opressão humana e atingir uma condição social e histórica livre de subjugação. É verdade que Saint-Simon e Comte não fizeram da tecnologia e do industrialismo ídolos, mas o seu voluntarismo progressista pôde ser apropriado por portadores do fetichismo industrial e tecnológico. Já as perspectivas que Emerson e Thoreau nos deixaram nos alvores das sociedades industriais são reveladoras de um espírito muito distinto do que aquele que levou à veneração da indústria, da tecnologia e da riqueza material. Elas oferecem-nos pistas para a imaginação sociológica bosquejar outra relação com a natureza, entre os seres humanos e os fins da vida; outra relação de confiança em cada um de nós que não passe por jogar aos deuses através do poder tecnológico, o qual por efeito de boomerang nos está afinal a conduzir à sujeição tecno-económica.

\section{BIBLIOGRAFIA}

CAREY, J. W. Technology and ideology. The case of the telegraph. In: Communication as culture. Essays on media and society. Minneapolis e Londres: University of Minnesota Press, 2009 [1983], p. 155-177.

\footnotetext{
${ }^{11}$ A respeito das tecnocatástrofes, ver, por exemplo, Dupuy (2002), Martins (2012, p. 255-301). Para uma análise de um episódio catastrófico concreto, ver Garcia e Jerónimo (2013).
} 
DUPUY, Jean- Pierre. Pour un catastrophisme éclairé. Paris: Points, 2002.

EMERSON, Ralph W. A confiança em si. In: A confiança em si, a natureza e outros ensaios. Lisboa: Relógio d' Água, 2009a [1841], p. 9-35.

A natureza. In: A confiança em si, a natureza e outros ensaios. Lisboa: Relógio d' Água, 2009b [1836]. p. 71-114.

A experiência. In: A confiança em si, a natureza e outros ensaios. Lisboa: Relógio d' Água, 2009c [1844], p. 137-161.

. Eulogy. Atlantic Monthly. 9 Maio, 1892.

GARCIA, José L. El discurso de la innovación en tela de juicio: tecnologia, mercado y bienestar humano. Arbor: ciencia, pensamiento e cultura. vol. 188, $\mathrm{n}^{\circ} 753,2012$, p.19-30.

GARCIA, José L. e JERÓNIMO, Helena M. (2013). Fukushima: a tsunami of technological order. In JERÓNIMO, Helena. M., GARCIA, José Luís \& MITCHAM, Carl (eds). Jacques Ellul and the techonological society in the 21st century. New York: Springer, pp. 129-144.

GARCIA, José L. e SUBTIL, Filipa. Conflito social e ambiente - a Ponte Vasco da Gama. Análise Social. vol. XXXIII (151-152), 1998 (2. $\left..^{\circ}-3 .^{\circ}\right)$, p. 707-746

GINER, Salvador. Piedad cósmica y racionalidade ecológica. In: Carisma y razón. La estructura moral de la sociedad moderna. Madrid: Alianza Editorial, 2003. p. 179-211.

HORKHEIMER, Max. O eclipse da razão. Lisboa: Antígona, 2015 [1947].

LACEY, Hugh. A controvérsia sobre os transgénicos. São Paulo, Ideia e Letras, 2006.

LÖWY, Michael. Utopias. Ensaios sobre política, história e religião. Lisboa: Ler Devagar, UNIPOP, 2016.

MARICONDA, Pablo R. e RAMOS, Maurício de Carvalho. Transgênicos e ética: a ameaça à imparcialidade científica. Scientia Studiae. Revista Latino-Americana de Filosofia da Ciência, vol. 1 (2), 2003, p. 245-261.

MARTINS, Hermínio. Para uma sociologia as calamidades. In: Experimentum Humanum. Civilização tecnológica e condição humana. Belo Horizonte: Editora Fino Traço, 2012, p. 255-301.

Dilemas da república tecnológica. In: Experimentum Humanum. Civilização tecnológica e condição humana. Belo Horizonte: Editora Fino Traço, 2012, p. 433-451.

MARX, Leo. Machine in the garden. Technology and the pastoral ideal in America. Oxford \& Nova Iorque: Oxford University Press, 2000 [1964]. 
A dominação da natureza e a redefinição do progresso. In: MARX, LEO e MAZLISH, BRUCE. Progresso: realidade ou ilusão? Lisboa: Editorial Bizâncio, 2001, p. 312-227 [1996].

McGINN, Robert E. Technology, Demography and the anachronism of traditional rights. Journal of Applied Philosophy, 11 (1), 1994, p. 57-70.

OLIVEIRA, Marcos Barbosa de. Inovação e neoliberalismo: a experiência brasileira. In: CALDART, Salete \& ALENTEJANO, Paulo (orgs.). Universidade e Pesquisa. São Paulo: Expressão Popular, 2014, p. 39-59.

PETERS, John D. Speaking into the air. A history of the idea of communication. Chicago \& Londres: The University of Chicago Press, 1999.

SOUZA, César Martins de. A estrada invisível. Histórias e memórias da Transamazônica. Curitiba, Paraná: Editora Prismas, 2018 (no prelo).

SUBTIL, Filipa. As Guerras Mundiais e as mutações na teoria social da comunicação e dos media. Revista FAMECOS: Mídia, Cultura e Tecnologia, Vol. 22 (3), p. 15-40, jul./set. 2015 .

Tecnologia, economia e política: o telégrafo como antecessor da Internet. Estudos em Comunicação, $n^{\circ} 15$ Esp, 2014, p. 25-40.

THOREAU, Henry D. Walden ou a vida nos bosques. Lisboa: Antígona, 2009 [1854].

Caminhada. Lisboa: Antígona, 2012 [1862].

[1849].

A week on the Concord and Merrimack rivers. Holt: Rinehart \& Winston, 1963

Uma vida sem princípios. Braga: Opera Omnis, 2014 [1863], p. 9-24 (com tradução, introdução e notas de Jaime Becerra da Costa). 